\title{
Slope stability monitoring in opencast coal mine based on wireless data acquisition system-a case study
}

\author{
Kumar Dorthi ${ }^{1 *}$, K. Ram Chandar ${ }^{2}$ \\ ${ }^{I}$ PhD Scholar, Department of Mining Engineering, NITK, Surathkal, Mangalore, India. \\ ${ }^{2}$ Asst. Professor, Department of Mining Engineering, NITK, Surathkal, Mangalore, India. \\ *Corresponding author E-mail:doreti.kumar@gmail.com
}

\begin{abstract}
Real time monitoring of slope failures is necessary to maintain the stability of slopes in open cast mines. A 3-level structure of Wireless Data Acquisition System (WDAQ) is developed for real time monitoring of slope deformation and analysis of data. In this paper, a case study is presented in a large opencast coal mine. Deformation in the slopes with slope angles of $49^{\circ}, 53^{\circ}, 58^{\circ}, 64^{\circ}, 68^{\circ}$ and $70^{\circ}$ is monitored over old underground workings. The deformation caused due to the external load like movement Heavy Earth Moving Machinery (HEMM). Maximum deformation was $1.57 \mathrm{~mm}$ for slope angle of $70^{\circ}$. It can be observed that the deformation increased with increased slope angle. This paper also describes that the validation of data based on WDAQ with the conventional method of monitoring as well as numerical modeling. The data obtained using WDAQ is in close to other two methods. The variation is around $11 \%$.
\end{abstract}

Index Terms: Wireless data acquisition system (WDAQ), Zigbee, galleries, partition, HEMM, numerical modeling.

\section{Introduction}

Advances in Information and Communication Technology (ICT) and wireless communications triggered development of lower power, less cost and multifunctional sensor [1]. Wireless Sensor Networks (WSNs) is an imminent technology that has a wide range of applications such as environmental monitoring, industrial automation, agriculture, disaster control, automotive, land slide prediction, structure health monitoring [2]. Wireless sensor networks consist of a large number of nodes connected together for sensing, communicating and processing. It consists of sensor nodes that organize themselves into a multi hop wireless network to convey information from one node to another [3].

Monitoring of slope stability in opencast mines is essential to avoid slope failures which lead to the damage of equipment, loss of production and loss of human lives also sometimes. There are conventional instruments for monitoring of slopes but they are wired technology and require physical presence of a person and these affected by atmospheric factors like fog and dust. Otherwise, wireless based slope stability radar system can be used but it is highly expensive [4]. However, Wireless Sensor Networks (WSNs) of low cost, low complexity, two way communication can be used for real time monitoring of slopes in opencast mine. In this paper, design and deployment of WDAQ with zigbee technology is discussed. Zigbee was used as wireless transmission of sensor data. It is low cost, low power consumption. It has flexibility to extend the network.

\section{Design of wireless DAQ}

A 3-level structure of Wireless DAQ consists of mainly three components: sensor node, Wireless Data Acquisition System (WDAQ) and processing unit or monitoring unit (Fig. 1). Level-1 consists of sensor node which is a group of sensors which are used to monitor an environment. After careful study, the geophysical sensor such as Linear Variable Differential Transformer (LVDT), needed for monitoring these phenomena was selected and installed. Linear Variable Differential Transformer (LVDT) is used to measure deformation. Its range is 0 to $50 \mathrm{~mm}$, operated temperature is 0 to $80^{\circ} \mathrm{C}$ and shaft type is spring loaded as shown in Fig. 2 .

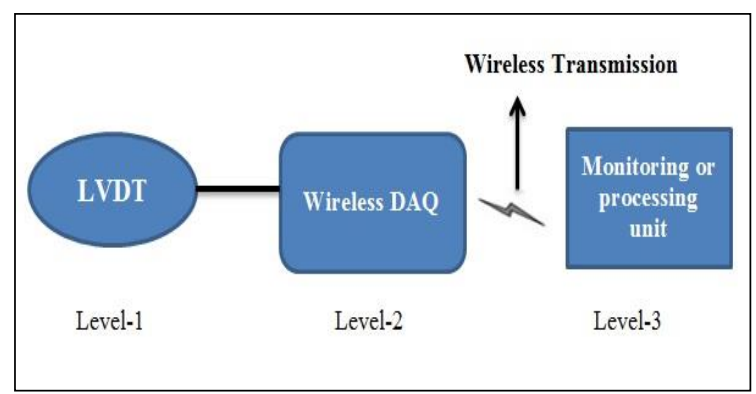

Fig. 1: Structure of 3-level wireless data acquisition system for monitoring slopes

Level-2 of the slope monitoring system consists of Wireless Data Acquisition System (WDAQ). It includes a microcontroller, Zigbee transceiver, Analog-to-Digital Converter (ADC) and Battery (Fig. 3). Wireless DAQ is responsible for gathering sensor's data from the field and convert to the system required format using ADC. After conversion, micro controller is used to process the data. In this, zigbee was used as data transmission system and to construct a wireless sensor environment for monitoring the slope in opencast mine. 


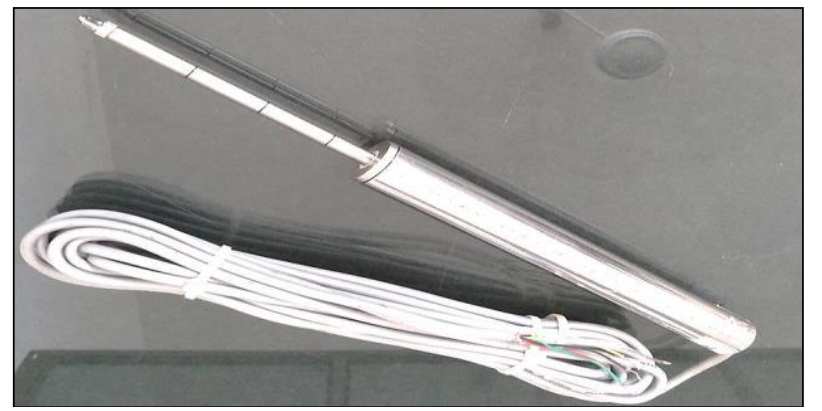

Fig. 2: A view of LVDT

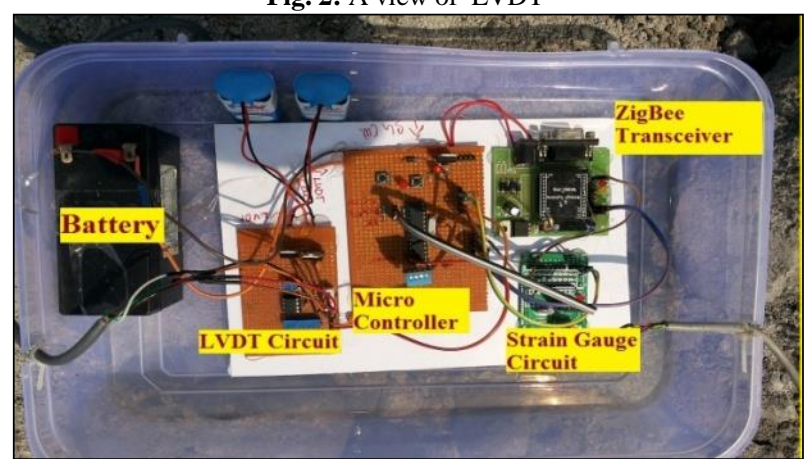

Fig. 3: Components of WDAQ

Level-3 comprises processing unit or monitoring unit. In this level, data was processed and displayed. Zigbee was used as wireless data transmission for sending generated data from WDAQ to monitoring point. It consists of transmitter and receiver. Zigbee wireless receiver received the data displayed on the remote system which was located at $100 \mathrm{~m}$ away from the monitoring point (Fig. 4). Data were observed continuously and processed by selfdeveloped software. The digital display of deformation values are shown with respect to the date and time in the display panel of the software (Fig. 5).

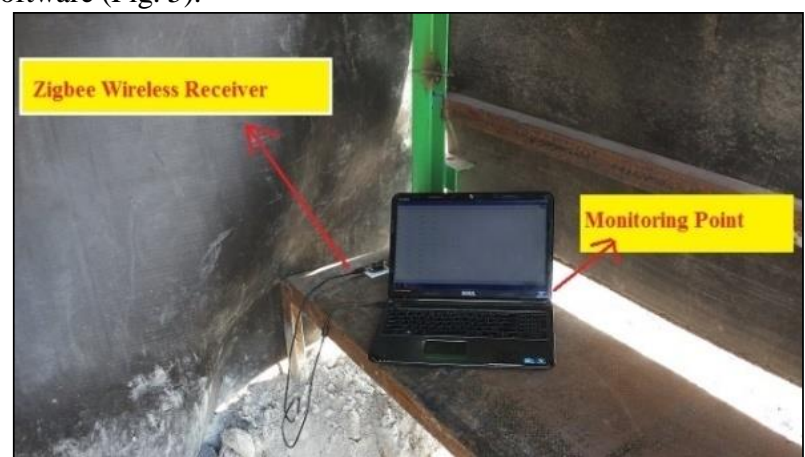

Fig. 4: Remotely monitoring in the field by Zigbee based WDAQ

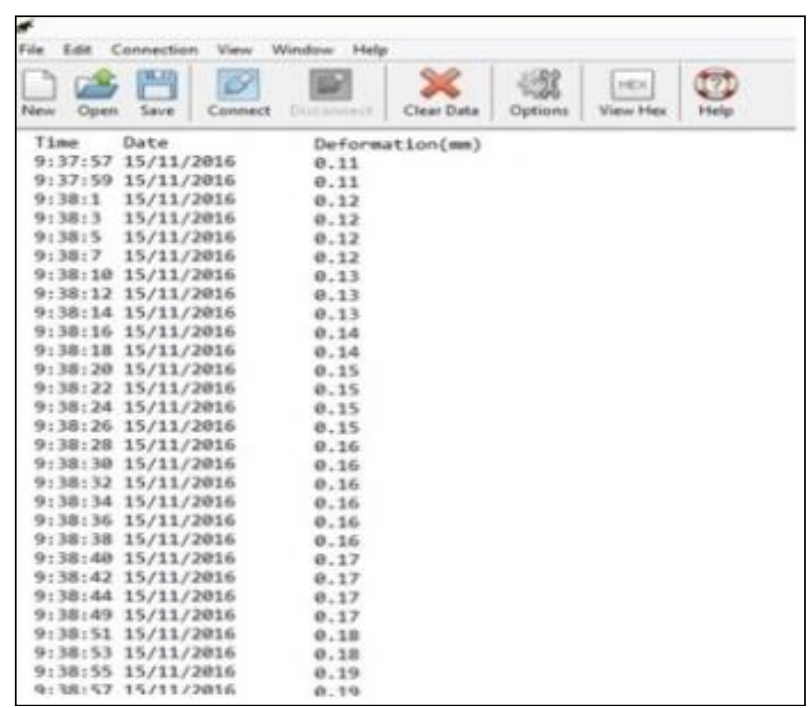

Fig. 5: Digital display of deformation in self-developed software

\section{Case study}

A case study is taken up to investigate the stability of slopes above old underground coal workings where coal is blocked in the form of pillars and extracted using surface mining methods in a large opencast mine in south India (Fig.6). View old underground coal workings are shown in Fig.7.
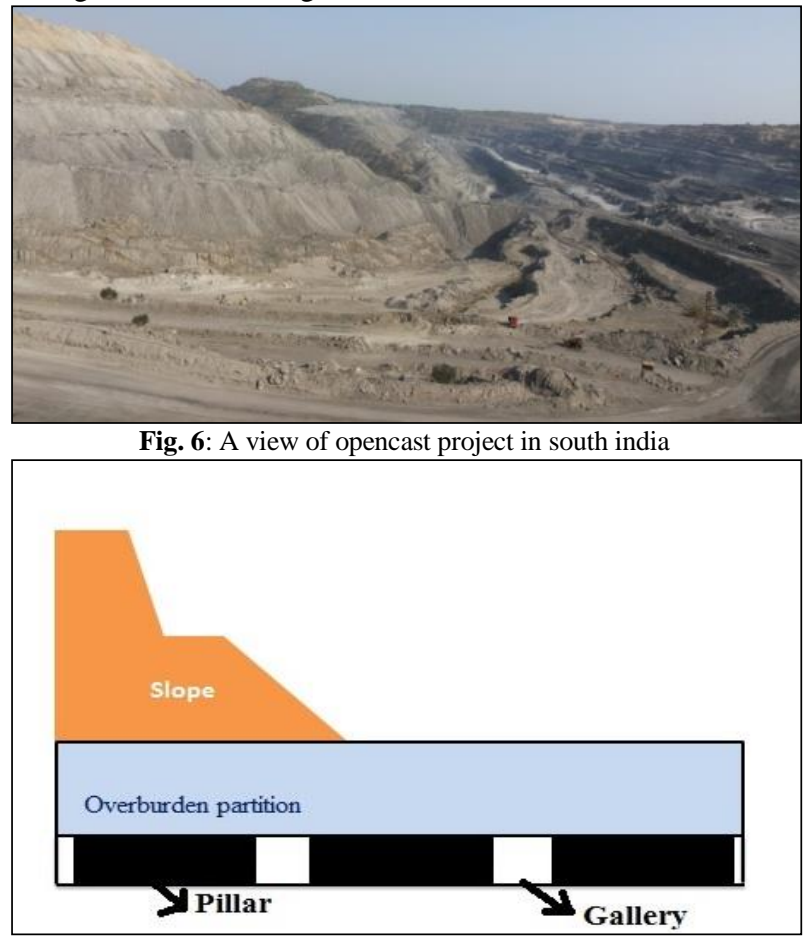

Fig. 7: Schematic diagram of old underground coal workings

There are many factors which affect the slopes over old underground workings include material properties of the partition, geometry of old workings and relative position of the underground workings to the mine bench as the bench progresses [5] Overburden partition thickness, movement of machinery and berm width were found to be critical parameters of stability of old galleries for extraction [6] [7]. As in "[8]" and "[9]", the stability of highwall mining which is closely related to monitoring of old workings. In this process, there are some problems associated with the conversion method like falling of men and machinery into old workings and slope failures over old underground galleries in some projects (Fig. 8).

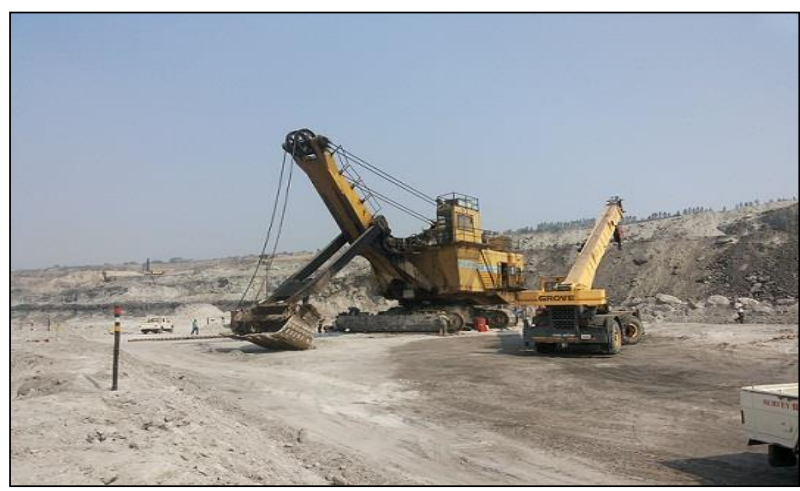

Fig. 8: A view of heavy earth moving machinery in large opencast mine

Geo-physical sensors were installed at different monitoring points, namely A, B and C over slopes above old underground galleries of height $3 \mathrm{~m}$ and width $4.2 \mathrm{~m}$ in the overburden (Fig. 9). Point ' $\mathrm{A}$ ' is toe of slope above the gallery whereas point ' $\mathrm{C}$ ' is the crest of slope and B is in between A and C in slope. Sensors were installed based on International Society for Rock Mechanics (ISRM) suggested methods [10] (Fig. 10). 


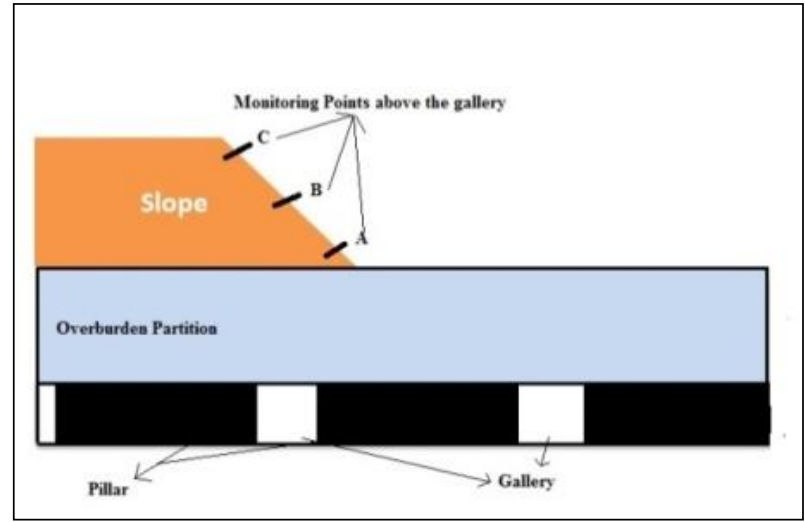

Fig. 9: Schematic diagram of monitoring points inthe site

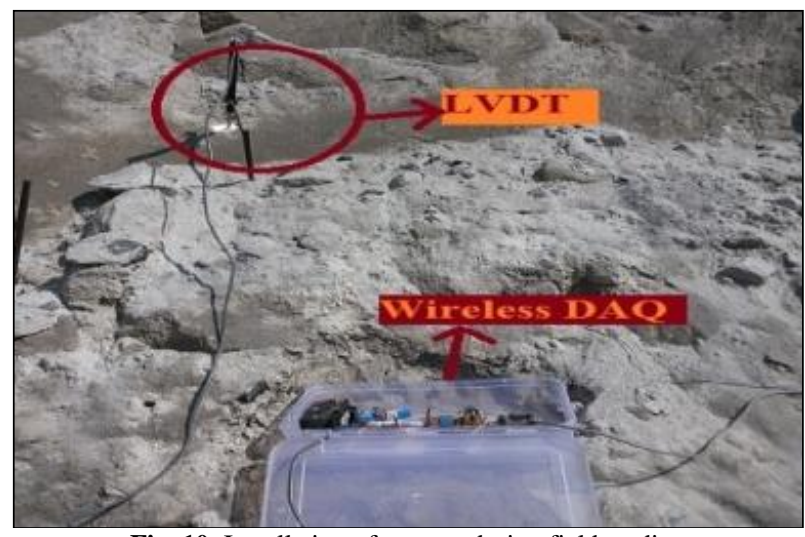

Fig. 10: Installation of sensors during field studies

Slopes with different angles of $49^{\circ}, 53^{\circ}, 58^{\circ}, 64^{\circ}, 68^{\circ}$ and $70^{\circ}$ above old underground galleries were considered for monitoring deformation due to the external load of HEMM. In this, each monitoring point (i.e. A, B and C) above the gallery was observed for 6-8 hours per day. Large quantity of data was generated on continuous monitoring from which minimum, maximum and average deformation values at each monitoring point is tabulated in Table I.

Table I: Variation in Deformation at Different Monitoring Point for Different Slope Angles Using Wireless DAQ

\begin{tabular}{|c|c|c|c|c|c|c|c|c|c|}
\hline \multirow{2}{*}{$\begin{array}{c}\text { Slope } \\
\text { Angle } \\
\text { (Degree) }\end{array}$} & \multicolumn{10}{|c|}{ Deformation(mm) } \\
\cline { 2 - 10 } & Monitoring Point- A & \multicolumn{2}{c|}{ Monitoring Point-B } & \multicolumn{2}{c|}{ Monitoring Point-C } \\
\hline 49 & Min & Max & Avg & Min & Max & Avg & Min & Max & Avg \\
\hline 53 & 0.01 & 1.17 & 0.59 & 0.01 & 0.81 & 0.41 & 0.01 & 0.68 & 0.35 \\
\hline 58 & 0.01 & 1.25 & 0.63 & 0.01 & 0.85 & 0.43 & 0.01 & 0.76 & 0.39 \\
\hline 64 & 0.01 & 1.29 & 0.65 & 0.01 & 0.95 & 0.48 & 0.01 & 0.88 & 0.45 \\
\hline 68 & 0.01 & 1.37 & 0.69 & 0.01 & 1.11 & 0.56 & 0.01 & 1.02 & 0.52 \\
\hline 70 & 0.01 & 1.41 & 0.71 & 0.01 & 1.24 & 0.63 & 0.01 & 1.18 & 0.60 \\
\hline
\end{tabular}

Comparison of variation in deformation at different monitoring points $\mathrm{A}, \mathrm{B}$ and $\mathrm{C}$ is given in Fig. 11. It can be seen that the deformation increased as slope angle increased. The maximum deformation of $1.57 \mathrm{~mm}$ was for $70^{\circ}$ and from $49^{\circ}$ to $68^{\circ}$ almost the deformation was increased gradually at monitoring point $\mathrm{A}$. Similarly, same trend was observed at point B and C also.

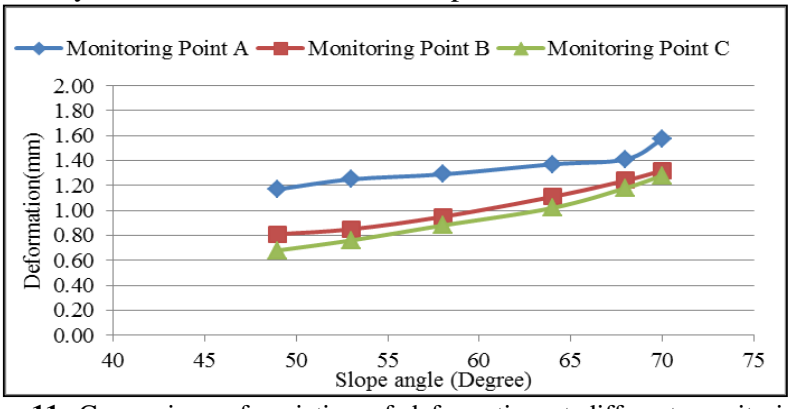

Fig. 11: Comparison of variation of deformation at different monitoring points

\section{Slope monitoring with Conventional instruments}

In order to validate the data generated by the 3-level structure of WDAQ, conventional data logger with the similar set of sensors was used. It is AH391-4 channel cabinet with LED display (Fig. 12). It is a 4 channel mainframe cabinet which is designed to house upto 4 measurement modules with LED display either for strain guage measurement or displacement measurement. Specifications of module are excitation for LVDT of $2 \mathrm{KHz}(2.0 \mathrm{Vrms}$ to 6.0 Vrms Adjustable), Low pass filter of $100 \mathrm{~Hz}$ and power source of $230 \mathrm{~V}$ AC. The output can be adjusted to +/- 1 to +/- 10V DC for full stroke of LVDT. Resolution of the module is $0.01 \mathrm{~mm}$. ADsof software was used to process the data generated by data logger as shown in Fig. 13.

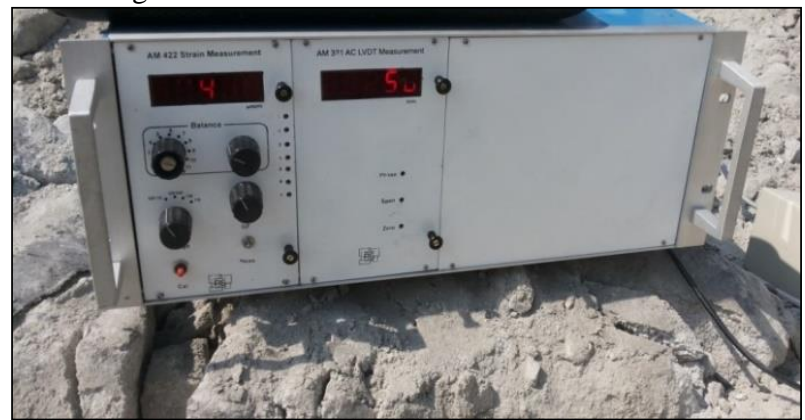

Fig. 12: Conventional data logger with display unit in the field

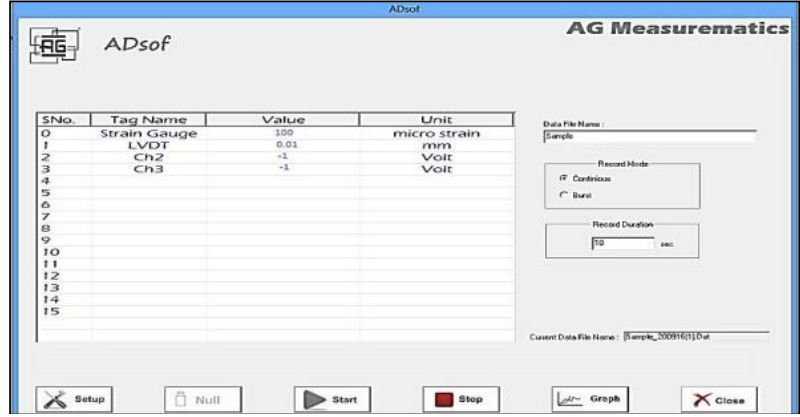

Fig. 13: Snapshot of ADsof software of conventional data logger Deformation was observed using LVDT at different locations in the slope above the old underground galleries. A large quantity of data was generated in conventional data logger on continuous monitoring from which minimum, maximum and average deformation at each monitoring point is tabulated in Table II.

Table II: Variation in Deformation at Different Monitoring Points for Different Slope Angles Using Data Logger

\begin{tabular}{|c|c|c|c|c|c|c|c|c|c|}
\hline \multirow{2}{*}{$\begin{array}{c}\text { Slope Angle } \\
\text { (Degrees) }\end{array}$} & \multicolumn{9}{|c|}{ Deformation(mm) } \\
\cline { 2 - 10 } & \multicolumn{2}{|c|}{ Monitoring Point-A } & \multicolumn{2}{c|}{ Monitoring Point-B } & \multicolumn{3}{c|}{ Monitoring Point-C } \\
\cline { 2 - 10 } & Min. & Max & Avg & Min & Max & Avg & Min & Max & Avg \\
\hline 49 & 0.01 & 1.03 & 0.52 & 0.01 & 0.65 & 0.33 & 0.01 & 0.63 & 0.32 \\
\hline 53 & 0.01 & 1.07 & 0.54 & 0.01 & 0.71 & 0.36 & 0.01 & 0.68 & 0.35 \\
\hline 58 & 0.01 & 1.17 & 0.59 & 0.01 & 0.77 & 0.39 & 0.01 & 0.75 & 0.38 \\
\hline 64 & 0.01 & 1.30 & 0.66 & 0.01 & 0.93 & 0.47 & 0.01 & 0.85 & 0.43 \\
\hline 68 & 0.01 & 1.36 & 0.69 & 0.01 & 1.06 & 0.54 & 0.01 & 1.01 & 0.51 \\
\hline 70 & 0.01 & 1.39 & 0.70 & 0.01 & 1.14 & 0.58 & 0.01 & 1.13 & 0.57 \\
\hline
\end{tabular}

Comparison of variation in deformation at different monitoring points $\mathrm{A}, \mathrm{B}$ and $\mathrm{C}$ is given in Fig. 14. As slope angle increased the deformation increased. The maximum deformation of $1.39 \mathrm{~mm}$ was for $70^{\circ}$ and from $49^{\circ}$ to $68^{\circ}$ the deformation was increased gradually at monitoring point $\mathrm{B}$. The maximum deformation occurred at monitoring point A. 


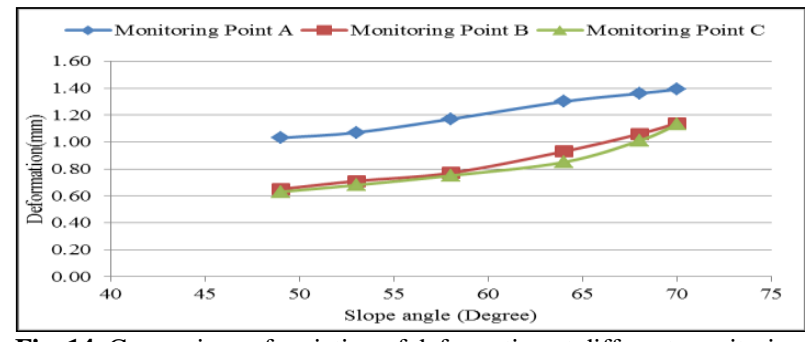

Fig. 14: Comparison of variation of deformation at different monitoring points

\section{Numerical modeling}

For further validation of data generated by the 3-level structure of WDAQ, numerical models were developed with similar field conditions. In order to study the vertical deformation in the slope above the old underground galleries, models were simulated using static structure module of ANSYS15 workbench (Fig. 15). Slope angles such as $49^{\circ}, 53^{\circ}, 58^{\circ}, 64^{\circ}, 68^{\circ}$ and $70^{\circ}$, were considered for this study and models were developed. Simulations were carried out on models to assess the deformation at toe, center and crest location of the slope above the old underground galleries.

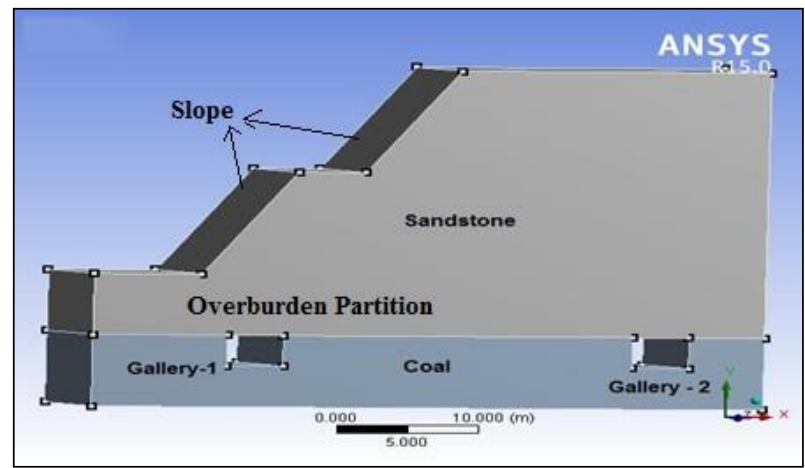

Fig. 15: Sketch of the mine benches over underground galleries

\section{Design parameters used to create models}

There are several parameters considered for the design of a model. They are as follows:

- Overburden (Sandstone) partition thickness and coal seam thickness considered for this study were $5.82 \mathrm{~m}$, $5.91 \mathrm{~m}, 6.26 \mathrm{~m}, 6.47 \mathrm{~m}, 6.74 \mathrm{~m}$ and $6.95 \mathrm{~m}$, and $7 \mathrm{~m}$ respectively.

- Different slope angles considered were for designing of models such as $49^{\circ}, 53^{\circ}, 58^{\circ}, 64^{\circ}, 68^{\circ}$ and $70^{\circ}$.

- Width of gallery and height of gallery were $4.2 \mathrm{~m}$ and $3 \mathrm{~m}$, separated by a center to center distance of $30.5 \mathrm{~m}$ pillars.

- Models were assigned with different material properties based on field conditions (Table III).

- Gravitational force acts along the centre of gravity of the combined mass.

- HEMM load was placed at surface center above the gallery. The Stress exerted by HEMM was taken as $3.7 \mathrm{x}$ $10^{6} \mathrm{~N}$.

- A rigid support was applied to the base of the model.

- Roller support was applied on either side.

Table III: Material Properties

\begin{tabular}{|l|l|l|}
\hline Property & Sandstone & Coal \\
\hline Young's Modulus $(\mathrm{GPa})$ & 25 & 3 \\
\hline Density $\left(\mathrm{kg} / \mathrm{m}^{3}\right)$ & 2450 & 1500 \\
\hline Poisson's Ratio & 0.25 & 0.22 \\
\hline Tensile Yield Strength $(\mathrm{MPa})$ & 1.38 & 0.23 \\
\hline Compressive Yield Strength $(\mathrm{MPa})$ & 142 & 25 \\
\hline
\end{tabular}

Application of boundary conditions and other supports are shown in Fig. 16.

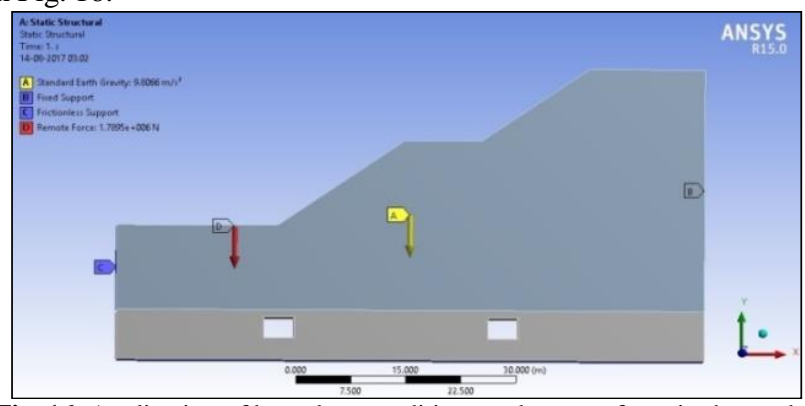

Fig. 16: Application of boundary conditions and remote force in the model After processing, ANSYS gives multicolored model which would be showing the deformation in the model (Fig. 17).

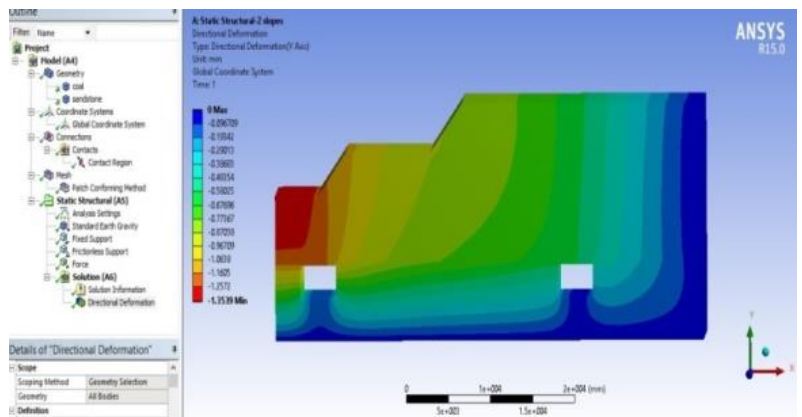

Fig. 17: Multi colored deformation on the model

Values of deformation at toe, center and crest locations of the slope above old workings of gallery width of $4.2 \mathrm{~m}$ and gallery height of $3 \mathrm{~m}$ for different slope angles are given in Table IV.

Table IV: Variation in deformation at different monitoring points for different slope angles using numerical modeling

\begin{tabular}{|c|c|c|c|}
\hline \multirow{2}{*}{$\begin{array}{c}\text { Slope Angle } \\
\text { Degrees) }\end{array}$} & \multicolumn{3}{|c|}{ Deformation(mm) } \\
\cline { 2 - 4 } & Monitoring Point-A & Monitoring Point-B & $\begin{array}{c}\text { Monitoring } \\
\text { Point-C }\end{array}$ \\
\cline { 2 - 4 } & Max. & Max. & Max. \\
\hline 49 & 1.36 & 1.05 & 0.99 \\
\hline 53 & 1.56 & 1.09 & 1.02 \\
\hline 58 & 1.59 & 1.16 & 1.11 \\
\hline 64 & 1.61 & 1.29 & 1.21 \\
\hline 68 & 1.72 & 1.51 & 1.44 \\
\hline 70 & 1.75 & 1.61 & 1.59 \\
\hline
\end{tabular}

Comparison of variation in deformation at different monitoring points A, B and C is given in Fig. 18. As slope angle increased the deformation also increased. The maximum deformation of $1.75 \mathrm{~mm}$ was for $70^{\circ}$ and from $49^{\circ}$ to $68^{\circ}$ the deformation increased gradually at monitoring point $\mathrm{A}$. The maximum deformation was occurred at monitoring point $\mathrm{A}$.

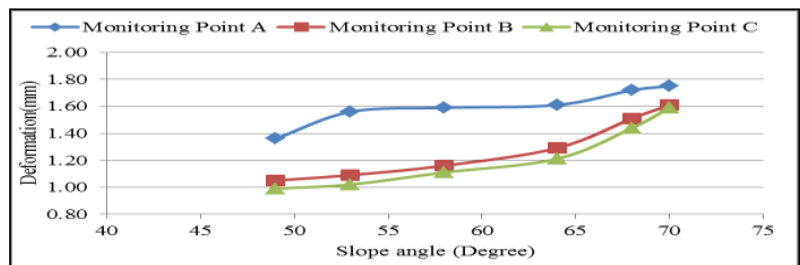

Fig. 18: Comparison of variation of deformation at different monitoring points

\section{Comparison of different slope monitoring methods}

Maximum deformation values of different slope angles monitored at different monitoring points $\mathrm{A}$ (at toe), $\mathrm{B}$ (at Center) and $\mathrm{C}$ (at crest) of slope above old underground galleries of height $3 \mathrm{~m}$ and gallery width of $4.2 \mathrm{~m}$ from data logger, WDAQ and numerical modeling is given in Table $\mathrm{V}$. 
Table V: Comparison of deformation of Data Logger, Numerical Modeling and Wireless DAQ

\begin{tabular}{|c|c|c|c|c|c|}
\hline \multirow{2}{*}{$\begin{array}{c}\text { Slope angle } \\
\text { (Degree) }\end{array}$} & \multicolumn{3}{|c|}{ Deformation (mm) } & \multicolumn{2}{c|}{ Error Rate (\%) } \\
\cline { 2 - 6 } & $\begin{array}{c}\text { Using } \\
\text { WDAQ }\end{array}$ & $\begin{array}{c}\text { Using Data } \\
\text { Logger (DL) }\end{array}$ & $\begin{array}{c}\text { Numerical } \\
\text { Modeling (NM) }\end{array}$ & $\begin{array}{c}\text { WDAQ } \\
\text { Vs. } \\
\text { DL }\end{array}$ & $\begin{array}{c}\text { WDAQ } \\
\text { Vs. } \\
\text { NM }\end{array}$ \\
\hline $\mathbf{4 9}$ & 1.17 & 1.03 & 1.36 & 11.97 & 13.97 \\
\hline $\mathbf{5 3}$ & 1.25 & 1.07 & 1.56 & 14.40 & 19.87 \\
\hline $\mathbf{5 8}$ & 1.29 & 1.17 & 1.59 & 9.30 & 18.87 \\
\hline $\mathbf{6 4}$ & 1.37 & 1.30 & 1.61 & 5.11 & 14.91 \\
\hline $\mathbf{6 8}$ & 1.41 & 1.36 & 1.72 & 3.55 & 18.02 \\
\hline $\mathbf{7 0}$ & 1.57 & 1.39 & 1.75 & 11.46 & 10.29 \\
\hline
\end{tabular}

DL-Data Logger, NM-Numerical Modeling.

The comparison of deformation in slope of numerical modeling, wireless DAQ and data logger is plotted in Fig.19. It can be observed that the trend of deformation in slope is increased with increasing slope angle and vice versa. Maximum and minimum deformation using numerical modeling, Wireless DAQ and data logger is $1.75 \mathrm{~mm}, 1.36 \mathrm{~mm}, 1.57 \mathrm{~mm}, 1.17 \mathrm{~mm}, 1.39 \mathrm{~mm}$ and $1.03 \mathrm{~mm}$ for slope angles $70^{\circ}$ and $49^{\circ}$ respectively. Deformation values of numerical modeling are more than the data logger and Wireless DAQ for all slope angles. It can also be observed that deformation observed by Wireless DAQ is more than conventional data logger. However, the data obtained using Wireless DAQ is in close to the other two methods.

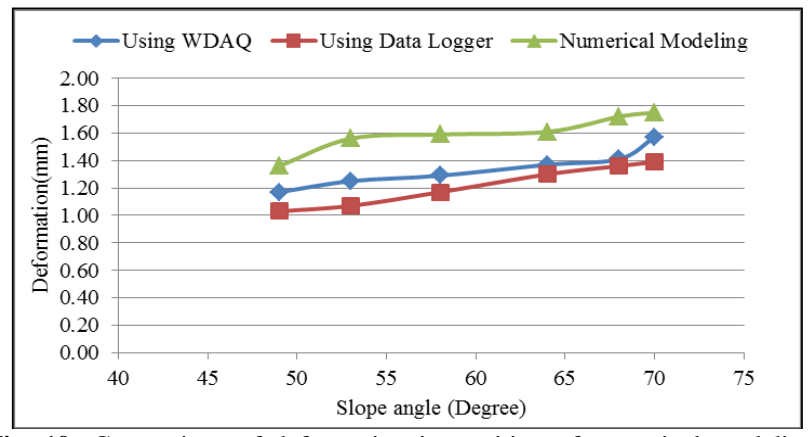

Fig. 19: Comparison of deformation in partition of numerical modeling, data logger and Wireless DAQ

\section{Conclusion}

In the present study, detailed field investigations were carried out for assessing the deformation in the slope above the old underground workings which are being converted into opencast mines in south India. To estimate deformation in slope, the 3-level structure of wireless DAQ is used. The study has led to draw the following conclusions:

- Deformation observed by the 3-level structure of wireless DAQ is slightly more than conventional data logger. Maximum deformation observed by data logger is $1.39 \mathrm{~mm}$, whereas $1.57 \mathrm{~mm}$ was observed by Wireless DAQ for slope angle of $70^{\circ}$. Variation is around $10 \%$, which is within acceptable limits.

- It can also be observed that the deformation generated by the 3-level structure of wireless DAQ is less than numerical modeling approach. Maximum deformation observed by numerical modeling is $1.75 \mathrm{~mm}$ whereas $1.57 \mathrm{~mm}$ was observed by wireless DAQ for slope angle of $70^{\circ}$. The variation is around $15 \%$, this is also almost within limits. This shows that the data obtained using WSN is reliable.

- Deformation was increased with increased slope angle and vice versa.

- The wireless monitoring of slopes is easy, convenient and reliable.

\section{References}

[1] Lin S, Liu J \& Fang Y, "ZigBee based wireless sensor networks and its applications in industrial", IEEE International Conference on Automation and Logistics, (2007), pp.1979-1983.

[2] Desai UB \& Jain BN, "Wireless sensor networks: technology roadmap", A Project supported by Department of Information Technology, Ministry of Information and Communication Technology, India, (2007).

[3] Dave TTC, Yuh-Show T \& Kai-Chun Y, "Study of real-time slope stability monitoring system using wireless sensor network", Telkomnika, Vol.11, No.3, (2013), pp.1478-1488.

[4] Kumar D \& Ram Chandar K, "Application of wireless sensor networks in slope stability monitoring-a critical review", The Indian Mining \& Engineering Journal, Vol.55, No.3, (2016), pp.29-32.

[5] Singh TN \& Singh DP, "Prediction of instability of slope in opencast mine over old surface and underground workings", International Journal of Surface Mining and Reclamation, (1992), pp.81-89.

[6] Kumar D, Ram Chandar K \& Alston DS, "Effect of partition of overburden on stability of old underground workings", Proc. INDORCOK-16, IIT Bombay, (2016), pp.950-970.

[7] Sastry VR \& Ram Chandar K, "Effect of berm width on stability of slopes- a case study.", Minetech Journal, Vol.34, No.2, (2013), pp.3-12.

[8] Ram Chandar K \& Gowtham Kumar B, "Effect of width of highwall mining gallery on stability of highwall", Int. Jl. Mining and Mineral Engineering, Vol.5, No.3, (2014), pp.212-228.

[9] Ram Chandar K, Chiranth H, Mohan Y \& Gowtham Kumar B, "Classification of stability of highwall during highwall mining: a statistical adaptive learning approach", Int. Jl. Geotechnical \& Geological Engineering, Vol.33, No.3, (2015), pp.511-521.

[10] Ulusay R \& Hudson JA, "The complete ISRM suggested methods for rock characterization, testing and monitoring: 1974-2006", Environmental and Engineering Geoscience, Vol.15, No.1, (2009), pp.47-48. 